Original Article (short paper)

\title{
Morphological and nociceptive effects of mechanical vibration on the sciatic nerve of oophorectomized Wistar rats
}

\author{
Camila Mayumi Martin Kakihata ${ }^{1}$, Ana Luiza Peretti ${ }^{1}$, Maria Luiza Serradourada Wutzke ${ }^{1}$, \\ Alana Ludemila de Freitas Tavares ${ }^{1}\left({ }^{10}\right.$, Lucinéia de Fátima Chasko Ribeiro' ${ }^{1}$, \\ Rose Meire Costa Brancalhão ${ }^{1}$, Gladson Ricardo Flor Bertolini ${ }^{1}(\mathbb{1}$ \\ ${ }^{1}$ Universidade Estadual do Oeste do Paraná, UNIOESTE, Cascavel, PR, Brasil
}

\begin{abstract}
Aim: To evaluate the effects of whole-body vibration in the sciatic nerve of oophorectomized Wistar rats, on nociceptive and morphological parameters, such as fiber, axon, and myelin sheath diameters, G ratio, number of nerve fiber and nuclei of Schwann cells, and percentage of connective tissue. Method: Sixty-four rats were used in the groups sham-operate and oophorectomy $(n=32$ /group); after surgical procedures, each group was subdivided into four: euthanized in the $12^{\text {th }}$ week, untreated and treated for four weeks; and euthanized in the $16^{\text {th }}$ week, untreated and treated for eight weeks. The treatment with vibration was performed with a $60 \mathrm{~Hz}$ frequencies, for 10 minutes, three days a week, with duration of 4 or 8 weeks. Nociception was evaluated later, in the right paw, by means of a digital analgesimeter, prior to surgery, at the beginning and at the end of the protocol. After the trial period, the sciatic nerve was dissected for examination of the general morphology of the tissue and morphometric analysis; later, the animals were euthanized. Results: Regarding nociception and the morphometry of the sciatic nerve, independent of oophorectomy and treatment time, there was no statistically significant difference within and between groups. Also, the general morphology of the tissue in all groups had characteristics that were preserved. Conclusion: The mechanical vibration did not alter the nociceptive threshold and the morphological aspects of nerve fibers in oophorectomized Wistar rats.
\end{abstract}

Keywords: ovariectomy; whole-body vibration; peripheral nervous system.

\section{Introduction}

With the increase in life expectancy, women spend a greater portion of their lives in the postmenopausal period, living together with the various changes that occur due to the decrease of estrogen ${ }^{1}$. This hormonal change affects several tissues, such as cardiovascular, urogenital ${ }^{2,3}$, nerve and bone tissue ${ }^{4,5}$. In the bone tissue, estrogen deficiency can enhance the loss of the bone matrix, resulting in osteoporosis, a disease characterized by decreased bone mineral density ${ }^{5,6}$.

One of the resources employed in the treatment of postmenopausal osteoporosis is vibration applied by a vibrating platform ${ }^{7}$, which can achieve anabolic responses following daily application for 5 to 20 minutes, 2 to 5 times a week ${ }^{7,22}$. Despite that stimulus being invoked as a form of treatment, exposure to vibration may cause tissue damage ${ }^{8}$. This potential for damage is commonly considered occupational, because the vibration is one of the causes of carpal tunnel syndrome, which has a high disease prevalence and promotes peripheral nerve injury $(\mathrm{PNI})^{3,9,10}$.

Damage to nervous tissue was observed in the experimental study of Govindaraju, Curry, Bain, Riley ${ }^{11}$, who used vibration with a frequency of 30,120 or $800 \mathrm{~Hz}$, for 4 continuous hours, which resulted in swelling within the nerve, with discontinuity of the myelin sheath and an increase in the diameter of the wall of the arterioles. The mechanisms of this type of injury are not immediately clear, but it is likely to affect the spine, because, during the whole-body vibration, a displacement may occur between the vertebrae. This can result in spinal degeneration, increased pressure, and rupture of the intervertebral discs, and consequent herniation ${ }^{10}$. This lesion of the intervertebral disk is allocated to the pathophysiology of sciatic nerve injury ${ }^{12}$.

The responses of therapy with a vibrating platform depend on the parameters to be used ${ }^{13}$, with time being a key variable, as prolonged exposure can cause damage to the tissue ${ }^{14-19}$. This prolonged exposure (daily and weekly) of the peripheral nerve to the vibration is widely studied in an occupational scope. However, there is a paucity of studies evaluating vibration as a therapeutic protocol, which, despite the short daily period, usually takes several weeks.

Thus, studies are needed to examine the effects of vibration on health ${ }^{10}$, enabling the determination of safety protocols of vibration ${ }^{8}$. Still, analysis of the influence of risk factors associated with PNI is necessary, such as that which occurs during the treatment of postmenopausal osteoporosis by means of mechanical vibration since both the vibration and the decrease in estrogen are risk factors for PNI; this has already been seen in carpal tunnel syndrome ${ }^{20}$. Thus, the aim of this study was to evaluate the effects of mechanical vibration on the sciatic nerve from oophorectomized Wistar rats, on nociceptive and morphological parameters, such as fiber, axon and myelin sheath diameters, $\mathrm{G}$ ratio, number of nerve fibers and nuclei of Schwann cells, and percentage of connective tissue. 


\section{Methods}

\section{Sample}

The sample was composed of sixty-four female Wistar rats, with an average body weight of $163.2 \pm 7.20 \mathrm{~g}$ and an age of eight weeks. The animals were kept in the Laboratory for Study of Injuries and Physical Therapy Resources (LELRF), in polypropylene boxes, with controlled conditions of temperature at $24 \pm 1^{\circ} \mathrm{C}$, a photoperiod of 12 hours of light/dark, and water and feed ad libitum. The animals were distributed into two groups, the sham-operated (SHAM) and oophorectomized (OVX) groups and then each was subdivided into 4 :

- $\quad$ SHAM $(\mathrm{n}=32)$ - sham-operated:

- $\quad$ SHAM $4(\mathrm{n}=8)$ - euthanized at the end of the $12^{\text {th }}$ week of the experiment;

- $\quad$ SHAM $8(\mathrm{n}=8)$ - euthanized at the end of the $16^{\text {th }}$ week of the experiment;

- $\quad$ SHAM-V4 $(\mathrm{n}=8)$ - mechanical vibration for 4 weeks and euthanized at the end of the $12^{\text {th }}$ week of the experiment;

- $\quad$ SHAM-V8 $(\mathrm{n}=8)$ - mechanical vibration for 8 weeks and euthanized at the end of the $16^{\text {th }}$ week of the experiment.

- $\operatorname{OVX}(\mathrm{n}=32)$ - ovariectomized:

- $\operatorname{OVX} 4(\mathrm{n}=8)$ - euthanized at the end of the $12^{\text {th }}$ week of the experiment;

- $\quad$ OVX $8(n=8)$ - euthanized at the end of the $16^{\text {th }}$ week of the experiment;

- $\quad$ OVX-V4 $(\mathrm{n}=8)$ - mechanical vibration for 4 weeks and euthanized at the end of the $12^{\text {th }}$ week of the experiment;

- $\quad$ OVX-V8 $(\mathrm{n}=8)$ - mechanical vibration for 8 weeks and euthanized at the end of the $16^{\text {th }}$ week of the experiment.

\section{Protocol for Oophorectomy and Sham Operations}

Initially, the animals were kept for 7 days in the LELRF vivarium for acclimatization. On the $8^{\text {th }}$ day, the rats were subjected to heavy and intraperitoneal anesthesia with ketamine hydrochloride (Dopalen, $80 \mathrm{mg} / \mathrm{kg}$ ) and xylazine hydrochloride (Anasedan, $20 \mathrm{mg} / \mathrm{kg}$ ) (Paulínia, São Paulo, Brazil). After the application of anesthesia and the verification of the state of consciousness of the animal (observed by the absence of motor response to the tail and clamping the interdigital folds), trichotomy with an alcohol-iodine solution in the abdomen in the region of the womb was performed using an aseptic technique. Then, a longitudinal incision, to access to the peritoneal cavity, was made; adipose tissue was removed until the fallopian tubes and ovaries could be identified.

In OVX animals, the uterine tubes were sutured with catgut 4.0 , followed by bilateral ovarian resection. At the end of the procedure, internal sutures were performed with absorbable catgut 4.0 simple sutures and external sutures, with 4.0 nylon wires; then, the region was treated with an alcohol-iodine solution. After the surgical procedure, the rats were located individually in polypropylene boxes, for three days, to recover ${ }^{21}$ and held for a total of 8 weeks without any intervention to determine the effects of hormonal deprivation. In the SHAM group, the surgical procedure was composed of performing all of the steps as for the oophorectomy group, except for the removal of the ovaries.

\section{Mechanical Vibration}

The vibration was applied using the Triplanar Vibration platform (Arktus ${ }^{\circledR}$, Santa Tereza do Oeste, Brazil), with a60 Hz frequency for 10 minutes and vibrations with average amplitude of $2 \mathrm{~mm}$; this was applied for three days interspersed by a week, with a two-day rest. The total period of intervention in the platform was about 4 weeks in the SHAM-V4 and OVX-V4 groups, from the $9^{\text {th }}$ until the $12^{\text {th }}$ week of the experiment, or 8 weeks in the SHAM-V8 and OVX-V8 groups, from the $9^{\text {th }}$ to the $16^{\text {th }}$ week of the experiment. For this, eight animals, separated by bays with a wide, length and height of $13 \times 19 \times 25 \mathrm{~cm}$, were positioned directly on the vibrating platform. The stalls were numbered 1 to 8 for rotation, clockwise, so that the animals passed through all of the parts of the platform.

\section{Evaluation of the Nociceptive Threshold}

The evaluation was carried out by means of a Von Frey Filament Type digital analgesimeter $\left(\right.$ Insight $^{\circledR}$, Ribeirão Preto, São Paulo). The animals were kept in high-floored box screens so that the tip of the polypropylene filament was applied perpendicularly in the region of the right hindlimb; this was performed with increasing pressure until the animal withdrew their limb. Prior to the beginning of the experiment, the animals were submitted to a stimulus with the filament for three days, simulating the assessment, for adaptation to the stimulus. In each assessment, the test was repeated three times and the average value was used; animals were always held by the same individual. The evaluation was performed in all groups prior to oophorectomy and sham operation (EV1) prior to the start of the protocol (EV2) and at the end of the experimental protocol (EV3).

\section{Histomorphometric Analysis of the Sciatic Nerve}

With properly anesthetized animals, dissection of the sciatic nerve was first performed, after which the animals were euthanized by an overdose of anesthetic, according to the intervention period of each group.

Two centimeters of the right sciatic nerve was dissected and removed, before being fixed in $4 \%$ paraformaldehyde in PBS ( $\mathrm{pH} 7.4$ ) for 48 hours and then stored in $70 \%$ alcohol to obtain nerve cross-sections with a thickness of $5 \mu \mathrm{m}^{23}$ on a microtome 
(Olympus BX60 ${ }^{\circledR}$, Tokyo, Japan). Subsequently, the cuts were stained with hematoxylin and eosin (HE) and analyzed regarding the general morphology of the tissue by light microscopy, by evaluating the presence of Schwann cells, and the integrity of nerve fibers and capillaries.

For the quantitative analysis, photomicrographs were taken with a 100x objective (4 fields). From this, the analyses were performed according to the modified protocol of a previous study $^{24}$. Measurements were made with a $50 \%$ zoom in the Image Pro plus 6.0 program $^{\circledR}$, in 100 fibers per animal, of the nerve fiber, axon and myelin diameters (the diameter of the myelin sheath was calculated by the diameter of the axon subtracted from that of the nerve fiber, divided by two); the $\mathrm{G}$ ratio, which is the ratio of the diameter of the myelin to the nerve fiber diameter, was also calculated. In addition, the number of small and larger nerve fibers of 4 micrometers and the number of nuclei of Schwann cells were counted, in a field of $50 \times 70 \mu \mathrm{m}$, with $50 \%$ zoom, including those on the edge "of inclusion" (top and left), but excluding those which touched the edge "of exclusion"(bottom and right). Histological sections were stained with Masson's trichrome, photomicrographed with a $100 \mathrm{x}$ objective (4 fields), and the percentage of connective tissue was measured in pixels, with a $50 \%$ zoom, using Image Pro plus $6.0^{\circledR}$.

\section{Analysis of the data}

The results were expressed by descriptive statistics and analyzed with the aid of the ExpDes.pt package of the program R (R Core Team, 2017) as to normal by Shapiro Wilk test, followed by three-way analysis of variance, and in the event of significance was the Tukey test-HSD. Was considered significant when $\mathrm{p}<0.05$.

\section{Ethical Aspects}

The project was approved by the Ethics Committee on the Use of Animals of Unioeste (CEUA) (24/08/2016), and was conducted according to the International Standards of Ethics in Animal Experimentation ${ }^{25}$.

\section{Results}

\section{Nociceptive Threshold}

Reagding the variety of nociception at the posterior right foot plantar region, there was no statistically significant difference between or within groups $(F=0.978, p=0.518)$ (Table 1). The oophorectomy and vibration, regardless of the time of application, did not change the nociceptive threshold of the rats.
Table 1. Nociceptive threshold of the right hind paw of Wistar rats

\begin{tabular}{lccc}
\hline & EV1 & EV2 & EV3 \\
\hline SHAM 4 & $35.88 \pm 5.04$ & $33.88 \pm 6.70$ & $34.07 \pm 7.07$ \\
OVX 4 & $33.35 \pm 6.02$ & $43.62 \pm 5.24$ & $37.62 \pm 8.19$ \\
SHAM-V4 & $35.21 \pm 5.85$ & $38.95 \pm 4.28$ & $39.58 \pm 8.88$ \\
OVX-V4 & $34.85 \pm 9.00$ & $39.79 \pm 4.36$ & $41.25 \pm 6.07$ \\
SHAM 8 & $30.44 \pm 11.72$ & $41.71 \pm 8.07$ & $38.40 \pm 10.40$ \\
OVX 8 & $39.66 \pm 4.40$ & $38.12 \pm 6.65$ & $38.13 \pm 5.25$ \\
SHAM-V8 & $35.28 \pm 9.25$ & $41.62 \pm 9.67$ & $37.16 \pm 8.11$ \\
OVX-V8 & $39.04 \pm 5.54$ & $34.51 \pm 7.57$ & $37.91 \pm 5.64$ \\
\hline
\end{tabular}

Mean \pm standard deviation. Periods of evaluation: prior to oophorectomy (EV1), prior to initiation of treatment (EV2) and at the end of treatment (EV3). SHAM 4 and SHAM 8: sham-operated groups of 4 and 8 weeks; OVX 4 and OVX 8: 4 and 8 weeks oophorectomy groups; SHAM-V4 and SHAM-V8: sham-operated groups submitted to vibration for 4 and 8 weeks; OVX-V4 and OVX-V8: oophorectomy groups submitted to vibration for 4 and 8 weeks.

\section{Morphology of the Sciatic Nerve}

Independent of oophorectomy and the intervention with vibration, all groups presented the sciatic nerve with features preserved, with healthy myelin nerve fibers, making it possible to identify the axon surrounded by the myelin sheath. There were few nuclei present, with those visible being Schwann cell-like, around the myelin sheath. The blood vessels showed a beneficial aspect, with most being capillaries (Figure 1).

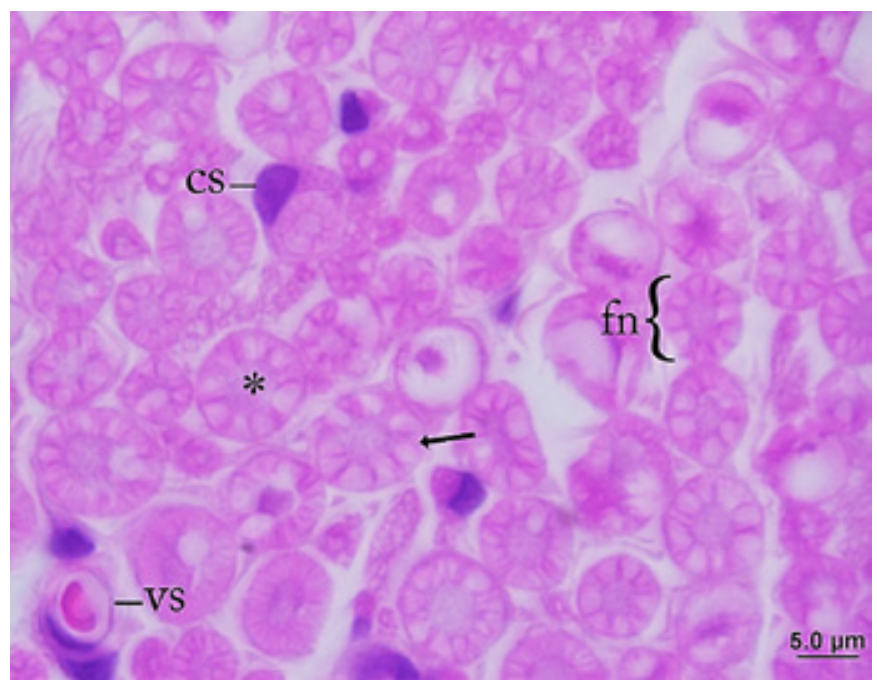

Figure 1. Photomicrography of the sciatic nerve, with a $100 \mathrm{x}$ objective, cross-sectional and stained with hematoxylin and eosin. The tip of the arrow indicates the myelin sheath; the asterisk is on the axon; vs - blood vessel; fn - myelin nerve fiber; and cs Schwann cell. The cut presents some artifacts of histological technique on the myelin sheath of some nerve fibers.Morphometry of the Sciatic Nerve

\section{Morphometry of the Sciatic Nerve}

In all variables, the data were normal and there were no statistically significant differences in the diameter of the nerve fiber, the axon and myelin sheath, $G$ ratio, percentage of 
connective tissue (Table 2), number of nerve fibers smaller and larger than 4 micrometers and number of nuclei of Schwann cells (Table 3). Thus, this denotes that oophorectomy and vibration did not change the morphometric parameters of the sciatic nerve. The values of the F-statistic and the $\mathrm{p}$ value for each variable are presented in Table 4.

Table 2. Diameter of nerve fiber, axon and myelin sheath $(\mu \mathrm{m}), \mathrm{G}$ ratio and percentage of connective tissue of the sciatic nerve of Wistar rats

\begin{tabular}{lccccc}
\hline & NerveFiber & Axon & Myelin & Gratio & Connectivetissue \\
\hline SHAM 4 & $5.55 \pm 0.64$ & $2.26 \pm 0.24$ & $1.64 \pm 0.24$ & $0.29 \pm 0.25$ & $50.08 \pm 4.22$ \\
OVX 4 & $5.33 \pm 0.28$ & $2.20 \pm 0.16$ & $1.56 \pm 0.10$ & $0.28 \pm 0.10$ & $51.16 \pm 5.69$ \\
SHAM-V4 & $5.49 \pm 0.32$ & $2.32 \pm 0.16$ & $1.58 \pm 0.20$ & $0.28 \pm 0.20$ & $54.76 \pm 7.15$ \\
OVX-V4 & $5.52 \pm 0.26$ & $2.30 \pm 0.17$ & $1.60 \pm 0.12$ & $0.28 \pm 0.12$ & $51.16 \pm 5.49$ \\
SHAM 8 & $5.52 \pm 0.53$ & $2.47 \pm 0.25$ & $1.52 \pm 0.26$ & $0.26 \pm 0.26$ & $51.47 \pm 5.02$ \\
OVX 8 & $5.39 \pm 0.48$ & $2.38 \pm 0.25$ & $1.50 \pm 0.15$ & $0.27 \pm 0.15$ & $54.80 \pm 6.41$ \\
SHAM-V8 & $5.38 \pm 0.33$ & $2.30 \pm 0.23$ & $1.53 \pm 0.13$ & $0.28 \pm 0.13$ & $50.95 \pm 4.32$ \\
OVX-V8 & $5.68 \pm 0.36$ & $2.45 \pm 0.34$ & $1.61 \pm 0.10$ & $0.27 \pm 0.10$ & $51.70 \pm 6.81$ \\
\hline
\end{tabular}

Mean \pm standard deviation. SHAM 4 and SHAM 8: sham-operated groups of 4 and 8 weeks; OVX 4 and OVX 8: 4 and 8 weeks oophorectomy groups; SHAM-V4 and SHAM-V8: sham-operated groups submitted to vibration for 4 and 8 weeks; OVX-V4 and OVX-V8: oophorectomy groups submitted to vibration for 4 and 8 weeks.

Table 3. Count of nerve fibers smaller in diameter and larger than $4 \mu \mathrm{m}$, and of Schwann cell nuclei, of the sciatic nerve of Wistar rats

\begin{tabular}{lccc}
\hline & Fiber $<\mathbf{4} \boldsymbol{\mu m}$ & Fiber $>\mathbf{4} \boldsymbol{\mu m}$ & Nuclei \\
\hline SHAM 4 & $17.59 \pm 9.75$ & $29.46 \pm 8.00$ & $5.31 \pm 1.51$ \\
OVX 4 & $16.75 \pm 6.77$ & $35.93 \pm 7.47$ & $5.34 \pm 1.44$ \\
SHAM-V4 & $13.28 \pm 6.44$ & $31.40 \pm 6.21$ & $5.71 \pm 1.24$ \\
OVX-V4 & $15.91 \pm 4.36$ & $35.96 \pm 5.75$ & $5.56 \pm 1.32$ \\
SHAM 8 & $14.58 \pm 6.53$ & $33.44 \pm 6.86$ & $4.84 \pm 1.09$ \\
OVX 8 & $15.00 \pm 3.96$ & $34.50 \pm 4.14$ & $5.90 \pm 1.23$ \\
SHAM-V8 & $11.53 \pm 3.81$ & $33.03 \pm 8.28$ & $4.81 \pm 0.90$ \\
OVX-V8 & $15.10 \pm 5.80$ & $34.17 \pm 4.78$ & $5.32 \pm 1.27$ \\
\hline
\end{tabular}

Mean \pm standard deviation. SHAM 4 and SHAM 8: sham-operated groups of 4 and 8 weeks; OVX 4 and OVX 8: 4 and 8 weeks oophorectomy groups; SHAM-V4 and SHAM-V8: sham-operated groups submitted to vibration for 4 and 8 weeks; OVX-V4 and OVX-V8: oophorectomy groups submitted to vibration for 4 and 8 weeks.

Table 4. Statistical values of nerve fiber diameter, axon and myelin sheath $(\mu \mathrm{m}), \mathrm{G}$ ratio and percentage of connective tissue, considering oophorectomy, vibration and time factors

\begin{tabular}{llcc}
\hline & Oophorectomy & Vibration & Time \\
\hline Nerve fiber & $\mathrm{F}=0.0079 ; \mathrm{p}=0.9655$ & $\mathrm{~F}=0.4101 ; \mathrm{p}=0.5245$ & $\mathrm{~F}=0.0278 ; \mathrm{p}=0.8830$ \\
Axon & $\mathrm{F}=0.0043 ; \mathrm{p}=0.9482$ & $\mathrm{~F}=0.0522 ; \mathrm{p}=0.8200$ & $\mathrm{~F}=4.9788 ; \mathrm{p}>0.05$ \\
Myelins heath & $\mathrm{F}=0.0012 ; \mathrm{p}=0.9721$ & $\mathrm{~F}=0.3731 ; \mathrm{p}=0.5438$ & $\mathrm{~F}=1.5092 ; \mathrm{p}=0.2243$ \\
Gratio & $\mathrm{F}=0.0657 ; \mathrm{p}=0.7987$ & $\mathrm{~F}=0.0657 ; \mathrm{p}=0.7987$ & $\mathrm{~F}=5.9250 ; \mathrm{p}>0.05$ \\
Connective tissue & $\mathrm{F}=0.0747 ; \mathrm{p}=0.7856$ & $\mathrm{~F}=0.0338 ; \mathrm{p}=0.8547$ & $\mathrm{~F}=0.0950 ; \mathrm{p}=0.7591$ \\
Fibre $<4 \mu \mathrm{m}$ & $\mathrm{F}=3.8387 ; \mathrm{p}=0.0551$ & $\mathrm{~F}=0.1337 ; \mathrm{p}=0.7160$ & $\mathrm{~F}=0.1675 ; \mathrm{p}=0.6839$ \\
Fibre $>4 \mu \mathrm{m}$ & $\mathrm{F}=0.0674 ; \mathrm{p}=0.3060$ & $\mathrm{~F}=1.4405 ; \mathrm{p}=0.2351$ & $\mathrm{~F}=1.6402 ; \mathrm{p}=0.2056$ \\
Nuclei & $\mathrm{F}=1.8166 ; \mathrm{p}=0.1831$ & $\mathrm{~F}=0.0002 ; \mathrm{p}=0.9898$ & $\mathrm{~F}=1.0635 ; \mathrm{p}=0.3068$ \\
\hline
\end{tabular}

Statistics F; $p$ value.

\section{Discussion}

Vibration has been demonstrated to have beneficial effects in the therapeutic field, such as in the increase in bone mass with 4 weeks of application ${ }^{22}$. However, it was observed that this stimulus could be harmful with an increase in exposure time by
8 weeks ${ }^{15}$. In this study, the parameters used in the therapeutic protocols were expanded to the peripheral nervous tissue, aiming to assist in the safety of the modality.

In the present study, we used whole-body vibration, applied through a vibrating platform. However, this did not change the nociceptive threshold and the morphological aspects of the nerve 
fibers. In addition, there was no changes in the diameter of the nerve fiber, the axon and myelin sheath, G ratio, the percentage of connective tissue, nerve fibers with a diameter greater than 4 micrometers and the number of nuclei of Schwann cells.

The vibration effects have been demonstrated to cause disabilities in the area treated because prolonged exposure to this stimulus can induce deleterious changes to various tissues. However, the adverse effects depend on the willingness of the individual, in addition to the vibration characteristics ${ }^{8}$. When vibration is applied to the entire body, it can impact the spine ${ }^{10,12}$, as observed in experimental studies where the application of $15 \mathrm{~Hz}$ vibrations for 30 minutes for up to 7 weeks promoted an increase in growth factors in intervertebral discs. This disc lesion may result in peripheral nerve injury, as observed by a reduction of the nociceptive threshold ${ }^{17,18}$.

In the present study, the vibration, using the parameters analyzed, showed no signs of injury to the sciatic nerve after 4 or 8 weeks. This divergence with the studies mentioned above could be due to the difference in cumulative dose, which is described as the total time of exposure to vibration and considers the number of weekly sessions and the duration of the stimulus ${ }^{14}$. In studies by Baig, Guarino, Lipschutz, Winkelstein ${ }^{18}$ and Kartha, Zeeman and Baig ${ }^{17}$, although the researchers used the vibration for only 7 days, they used twice the daily time of the present study. In addition, Baig, Guarino, Lipschutz, Winkelstein ${ }^{18}$ noted that the higher the frequency and absolute period of weekly therapy, the more serious the changes were. In contrast, in this study, the interventions took place at a low weekly frequency, just 3 days a week, justifying the results found ${ }^{18}$.

In the study by Yan, Zhang, Agresti, Giudice, Sanger, Matloub, Havlik ${ }^{19}$, deleterious effects of long-term vibration were observed in the nerve tissue of rats. Vibration of $30 \mathrm{~Hz}$, $0.5 \mathrm{G}$, for 4 hours, 5 days per week, for 2,4 or 8 weeks was applied to the whole body, and central nervous system(CNS) damage was observed as a thickening of the capillaries with the proliferation of fibroblasts and vacuoles in the smooth muscle, as well as functional changes. In addition, there was a decrease in the nociceptive threshold and grip strength, and all these changes had further increased along with the vibration exposure period, showing the probable cumulative effect of this stimulation. Despite the weekly number corresponding to that used in the present study, Yan, , Zhang, Agresti, Giudice, Sanger, Matloub, Havlik ${ }^{19}$ had a greater weekly frequency and duration of daily exposure.

Vascular changes were also observed in the study of Govindaraju, Curry, Bain, Riley ${ }^{11}$, whose vibration, in a single application, with a frequency of 30,120 or $800 \mathrm{~Hz}$ for 4 hours, promoted dilation of the arterioles with thickening of the walls of these vessels. In addition, the vibration caused neural edema and promoted changes in the myelin sheath of the nerve fiber of rats. This reaffirms that the vibration during prolonged exposure (4 hours), as stated by Govindaraju, Curry, Bain, Riley ${ }^{11}$ and Yan, Zhang, Agresti, Giudice, Sanger, Matloub, Havlik ${ }^{19}$, can promote nerve lesions, which contrast with the findings in the present study, using a shorter time. This suggests that the total time of therapy is not the main risk factor for peripheral nerve injury because the application for up to 8 weeks, in low parameters of daily time and weekly frequency, as used in this study, does not affect the sciatic nerve of rats.

In addition to the vibration, there are other factors that increase the likelihood of PNI, such as vitamin deficiencies, systemic diseases, metabolic and endocrine disorders, and hormonal imbalances like estrogen deficiency ${ }^{20,26,27}$. As a result of the menopause, the prevalence of carpal tunnel syndrome is owned by four times greater in women than in men $^{26-28}$. This hormonal influence on the nervous tissue can occur due to the protective effect that is discussed from observations of the sex-differences in the responses to CNS injury. With this, it was found that premenopausal women feature less neurological damage in the CNS and a better recovery compared with men; however, after the menopause, this damage is equivalent ${ }^{29}$. In the peripheral nervous system, studies have noted the beneficial effect of estrogen replacement on sciatic nerve regeneration after injury by compression in oophorectomized rats ${ }^{30,31}$.

These findings show that estrogen has a protective effect on nerve tissue, which can be reversed with the menopause. These studies are different from the results of the current study, where hormonal deprivation for 12 and 16 weeks, alone, or associated with vibration, did not alter the nociceptive threshold and characteristics of peripheral nerve fibers. This probably occurred because, in the studies mentioned above, the protective effects of estrogen medicate prior injuries; this hormonal deprivation study was analyzed without the presence of prior damage to nerve tissue.

Thus, it is possible to observe that vibration in the analyzed parameters, applied for 4 and 8 weeks, at a small daily and weekly frequency, and estrogen deficiency after oophorectomy, alone or associated with vibration, did not promote signs of peripheral nerve injury. However, it is suggested that studies to assess the safety of long-term vibration protocols, in therapeutic practice, on the peripheral nerve, should be performed, evaluating the expression of growth factors and inflammatory cytokines, which is a limitation of this study.

\section{Conclusion}

Whole-body vibration for 4 and 8 weeks, in the sciatic nerve of oophorectomized Wistar rats, did not alter the nociceptive threshold or morphological aspects, such as fiber, axon and myelin sheath diameters, $G$ ratio, number of nerve fiber, and nuclei of Schwann cells, and the percentage of connective tissue.

\section{References}

1. Engler-Chiurazzi EB, Brown CM, Povroznik JM, Simpkins JW. Estrogens as neuroprotectants: estrogenic actions in the context of cognitive aging and brain injury. Prog Neurobiol. 2015; 157 (1): 188-211.

2. Al-Safi ZA, Santoro N. Menopausal hormone therapy and menopausal symptoms. Fertil Steril. 2014; 101 (4): 905-15.

3. Newington L, Harris C, Walker-bone K. B. Carpal tunnel syndrome and work. Best Pract Res Clin Rheumatol. 2015; 29 (3): 440-53. 
4. Ji M, Yu Q. Primary osteoporosis in postmenopausal women. chronic Dis Transl Med. 2015; 1 (1): 9-13.

5. Tella SH, Gallagher JC. Prevention and treatment of postmenopausal osteoporosis. J Steroid Biochem Mol Biol. 2014; 142 (1): 155-70.

6. Radominski CS, Bernardo W, Paula A, Albergaria B, Moreira $\mathrm{C}$, Fernandes CE, et al. Diretrizes brasileiras para o diagnóstico e tratamento da osteoporose em mulheres na pós-menopausa. Rev Bras Reumatol. 2017; 7 (2): 452-66.

7. Weber-Rajek M, Mieszkowski J, Niespodziński B, Ciechanowska $\mathrm{K}$. Whole-body vibration exercise in postmenopausal osteoporosis. Prz menopauzalny. 2015; 14 (1): 41-7.

8. Cardinale M, Pope MH. The effects of whole body vibration on humans: dangerous or advantageous? Acta Physiol Hung. 2003; 90 (3): 195-206.

9. Chammas M. Carpal tunnel syndrome. Chir Main. 2014; 33 (2): 75-94.

10. Palmer KT, Bovenzi M. Rheumatic effects of vibration at work. Best Pract Res Clin Rheumatol. 2015; 29 (1): 424-39.

11. Govindaraju SR, Curry BD, Bain JLW, Riley DA. Nerve damage occurs at a wide range of vibration frequencies. Int J Ind Ergon. 2008; 38 (1): 687-92.

12. Stafford MA, Peng P, Hill DA. Sciatica: a review of history, epidemiology, pathogenesis, and the role of epidural steroid injection in management. Br J Anaesth. 2007; 99 (4): 461-73.

13. Dionello CF, Sá-Caputo D, Pereira HVFS, Souza-Gonçalves CR, Maiworm AI, Morel DS, et al. Effects of whole body vibration exercises on bone mineral density of women with postmenopausal osteoporosis without medications: novel findings and literature review. J Musculoskelet Neuronal Interact. 2016; 16 (3): 193-203.

14. Fratini A, Bonci T, Bull AMJ. Whole body vibration treatments in postmenopausal women can improve bone mineral density: results of a stimulus focussed meta-analyis. PLoS One. 2016; 11 (12): e0166774.

15. Xie P, Tang Z, Qing F, Chen X, Zhu X, Fan Y, et al. Bone mineral density, microarchitectural and mechanical alterations of osteoporotic rat bone under long-term whole-body vibration therapy. J Mech Behav Biomed Mater. 2016; 53 (1): 341-9.

16. Moreira-Marconi E, Dionello CF, Danielle SM, Sá-Caputo D, Souza-Gonçalves CR, Paineiras-Domingos LL, et al. Could whole body vibration exercises influence the risk factors for fractures in women with osteoporosis? Osteoporosois and Sarcopenia. 2016; 2 (4): 214-20.

17. Kartha S, Zeeman ME, Baig HA. Upregulation of BDNF \& NGF in cervical intervertebral discs exposed to painful whole body vibration. Spine. 2015; 39 (19): 1542-8.

18. Baig HA, Guarino BB, Lipschutz D, Winkelstein BA. Whole body vibration induces forepaw and hind paw behavioral sensitivity in the rat. J Orthop Res. 2013; 31 (11): 1739-44.

19. Yan JG, Zhang L, Agresti M, Giudice JL, Sanger JR, Matloub HS, Havlik R. Neural systemic impairment from whole-body vibration. J Neurosci Res. 2015; 93 (5): 736-44.

20. Haylock-vize P, Souza, RM, Choi D. Peripheral nerve lesions. Surgery. 2015; 33 (8): 377-83.

21. Khajuria DK, Razdan R, Mahapatra DR. Descrição de um novo método de ooforectomia em ratas. Rev Bras Reumatol, vol. 52, no. 3, pp. 466-470, 2012.
22. M. M. Butezloff, A. Zamarioli, G. B. Leoni, and J. B. Volpon, "Whole-body vibration improves fracture healing and bone quality in rats with ovariectomy-induced osteoporosis. Acta Cirúrgica Bras. vol. 30, no. 11, pp. 727-735, 2015.

23. Junqueira LC, Junqueira LMMS. Técnicas básicas de citologia e histologia. Ed Santos, São Paulo, 1983.

24. Kakihata CMM, Malanotte JA, Brancalhão RMC, Ribeiro LFC, Bertolini GRF. The morphological and functional effects of exercise in the aquatic environment, performed before and / or after sciatic nerve compression in Wistar rats. J Exerc Rehabil. 2016; 12 (5): 393-400.

25. Andersen ML, D’Almeida V, Ko GM, Kawakami R, Martins PJ, Magalhães LE, et al. Princípios éticos e práticos do uso de animais de experimentação. Ed UNIFESP, São Paulo, 2004.

26. Kaplan Y, Kurt SG, Karaer H. Carpal tunnel syndrome in postmenopausal women. J Neurol Sci. 2008; 270 (1): 77-81.

27. Thurston A. Carpal tunnel syndrome. Orthop Trauma. 2013; 27 (5): 332-41.

28. Padua L, Coraci D, Erra C, Pazzaglia C, Paolasso I, Loreti C, et al. Carpal tunnel syndrome: clinical features, diagnosis, and management. Lancet Neurol. 2016; 15 (1): 1273-84.

29. Leon RL, Huber JD, Rosen CL, Virginia W. Potential ade-dependent effects o estrogen on neural injury. Am J Pathol. 2011; 178 (6): 2450-60.

30. Islamov RR, Hendricks WA, Jones RJ, Lyall GJ, Spanier NS, Murashov AK. 17 b-Estradiol stimulates regeneration of sciatic nerve in female mice. Brain Res. 2002; 943 (1): 283-6.

31. Islamov RR, Hendricks WA, Katwa LC, Mcmurray RJ, Pak ES, Spanier NS, et al. Effect of $17 \mathrm{~b}$-estradiol on gene expression in lumbar spinal cord following sciatic nerve crush injury in ovariectomized mice. Brain. 2003; 966 (1): 65-75.

\section{Acknowledgements}

The Fundação Araucária, for financial support (Edital de Pesquisa Básica e Aplicada) and the Coordenação de Aperfeiçoamento de Pessoal de Nível Superior (CAPES).

\section{Corresponding author}

Gladson Ricardo Flor Bertolini

Rua Universitária, 2069, Jardim Universitário. CEP: 85819-110. Cascavel, PR, Brasil.

Fone/ Fax: 3220-3157 ou 3220-3236

Email: gladson_ricardo@yahoo.com.br

Manuscript received on March 26, 2018

Manuscript accepted on October 25, 2018

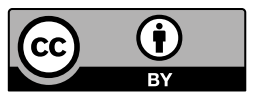

Motriz. The Journal of Physical Education. UNESP. Rio Claro, SP, Brazil - eISSN: 1980-6574 - under a license Creative Commons - Version 4.0 